\title{
A centralised cytology screening programme for cervical cancer in Florence
}

\author{
Domenico Palli, Simona Carli, Silvia Cecchini, Antonella Venturini, Giovanna Piazzesi, \\ Eva Buiatti
}

\begin{abstract}
Study objective-The aim of the study was to evaluate the effectiveness of a centralised population based cervical cytology screening programme.

Design-The study was a case-control investigation.

Setting-Cases and controls were confined to the province of Florence.

Participants-191 out of 208 cases of cervical cancer in women $<75$ years old at diagnosis in the period 1982-85 were interviewed. For each case three living controls were selected, strictly matched by year of birth and district of residence; in all 573 controls were eventually identified. Of these, 15 had had a hysterectomy $(2.6 \%)$ and were excluded, and a further $18(3.2 \%)$ did not take part for other reasons, leaving a total of 540 controls.

Measurement and results-Screening history was taken from a computerised archive for both cases and controls. A mail questionnaire was used to collect information on several potential confounding variables. For women screened only once in comparison with those never screened, the reduction in risk was about $70 \%$ (odds ratio $0 \cdot 29.95 \%$ confidence limits $0.15-0.55)$, while the reduction was even greater for those screened twice or more. No trend of increasing risk with increasing interval since last test was shown: considering separately women who had only had one test and those who had had two or more tests, the risk estimates were stable across different time intervals since the last test.
\end{abstract}

Conclusions-There is a strong protective effect against developing invasive cervical cancer through participation in the screening programme.

Centro per lo Studio e la Prevenzione Oncologica, Viale A

Volta 171, 50131

Florence, Italy:

Epidemiology Unit

D Palli

$S$ Carli

A Venturini

G Piazzesi

E Buiatti

Cervical Cancer

Screening

Programme

$S$ Cecchini

Correspondence to: Dr Palli

Accepted for publication July 1989
In the Florence Province a programme for cervical cancer screening is currently run by the Centre for Study and Prevention of Oncological diseases (CSPO). The resident female population aged between 18 and 60 years is periodically invited to undergo a Papanicolaou smear (Pap smear) (the total female population of the area at the 1981 National Census was 635604 ; about 340000 women were in the 18-60 year age group).

This regular invitation protocol was started only in 1980. In previous years access was free for self referred women: on average in the period 1970-1974, 40000 examinations were carried out per year, while in the period 1975-1979 the examinations increased to 50000 per year.
When they have been taken, the cytology smears are sent to the centralised laboratory at CSPO which also maintains a computerised archive of all the information collected (on average 70000 vaginal cytology smears have been examined annually since 1980). Colposcopy has been available since 1978 and approximately $10 \%$ of the screened women have been examined (currently around 8000 colposcopy examinations are performed per year). Participation in the programme is completely free.

The aim of the present study was to evaluate the effectiveness of this screening programme, using the data available in the computerised archives relating to all Pap smears carried out since 1970 .

The study design chosen was of the casecontrol type, used recently not only to evaluate the efficacy of this type of screening ${ }^{1-4}$ but also to evaluate programmes for breast cancer screening in Europe ${ }^{5-7}$ and more recently for gastric cancer in Japan $^{8}$ and lung cancer in Germany. ${ }^{9}$

The use of this study design in the evaluation of screening programmes has recently been reviewed by various authors. ${ }^{10}{ }^{11}$ It is important to emphasise that no data derived from controlled studies are available for evaluating screening programmes for this cancer, as there are for breast cancer, where there is also solid evidence from randomised studies. ${ }^{12} 13$

The local cancer registry (Registro Tumori Toscano or RTT) came into being on January 1 1984. For the years $1975-1983$ a preliminary study had identified the women resident in the Province of Florence and diagnosed with cervical cancer with histological confirmation. Cases identified as "incident" in the years 1975-81 were not used in the this study in order to ensure maximum reliability of the incidence date. These cases formed an archive of "prevalent" cases.

The incidence rate of cancer of the uterine cervix in the province of Florence for 1985 has been estimated by the RTT, the European standardised rate being $9 \cdot 3$ per 100000 women. $^{14}$

\section{Methods}

CASES

Women diagnosed with invasive cervical cancer in the years 1982-1985 with histological confirmation and resident in the Province of Florence were considered as cases. All cases aged 75 years and over at the time of diagnosis were excluded.

Overall in the period 1982-1985, 208 cases of cervical cancer with age at diagnosis less than 75 years were identified; 42 cases were already dead at the time of the study and the interviews were conducted, when possible, with surviving 
relatives. In total 191 cases or their relatives were interviewed $(91.8 \%)$.

\section{CONTROLS}

For each case, three living women were identified, being strictly matched according to year of birth and district of residence. All women had to be resident in the Province of Florence after 1970) or at least since 1970 . The population controls were sampled from the town registry lists.

Fifteen women out of 573 had had a total hysterectomy before the diagnosis date of the matched case and were excluded $(2 \cdot 6 \%)$. Only the controls originally matched to interviewed cases were considered. Overall 540 controls out of the 558 identified and eligible were interviewed and used in the study $(96.8 \%)$. Refusals were fewer than $1 \%$.

\section{SCREENING HISTORY}

Only the Pap tests carried out at least six months before the diagnosis were considered valid, as in later months these are often carried out with symptoms already present and should be considered as "diagnostic" smears. The same date (six months before the diagnosis of the case or Useful date) was used for matched controls. Pap tests resulting in Papanicolaou class 1 or 2 were considered negative. Previous positive tests (class 3) were identified in four subjects: three cases and one control.

Information on the number, date and results of the examinations carried out was taken from the computerised archive available at CSPO, both for cases and controls. This source should be considered more reliable than the history taken from the women since it is often difficult for women to remember precisely the number and dates of Pap tests carried out. Comparability of information between cases and controls should be higher since it is obtained from only one source. Women affected by cervical cancer may be more likely than their controls to remember the number and dates of previous Pap tests.

At the end of the study the screening history of a random sample of 100 controls was checked in order to verify the accuracy of the information stored in the CSPO archive.

The sampled women were reinterviewed by telephone, and asked if the dates and numbers of Pap tests obtained from the CSPO computerised archive were exact. However we only used the information originally collected from the archive.

\section{QUESTIONNAIRE}

A questionnaire with prepaid reply envelope was sent to the home addresses of all living cases and controls. If a reply was not received, a reminder was sent out within a month of the first. If this too received no response, the questionnaire was conducted by telephone. Home interviews were carried out for all cases and controls not contacted by telephone.

For deceased cases, contact was made with family members (husband, children, sisters or mother) by a specific letter to the last known address.

No direct question concerning sexual habits (age at first intercourse or number of partners) or screening history was present in the questionnaire.
ANALYSIS

All the data were analysed by initially considering the number of smears carried out and then by considering the interval since the last test. The analysis was carried out with a conditional logistic model, using the PHGLM procedure in the SAS statistical package, ${ }^{15}$ available on the IBM 3083 mainframe of the Tuscany Regional Council.

Crude odds ratios (conditional logistic model without confounding variables) and adjusted odds ratios were estimated. A $\chi^{2}$ test was used to evaluate differences in the distribution of confounding variables. The potential confounders were categorised as follows:

- place of birth (Florence district, centralnorthern Italy, southern Italy)

- civil status (married/widow, never married, divorced)

- socioeconomic level (low, high)

- number of children $(0,1-2,3+)$

- number of abortions $(0,1+)$

- smoking history (non-smokers, current smokers, ex-smokers)

- level of education (less than 8 years/8 years or more)

- age at first marriage $(<21,21+$ years, never married)

- age at menarche $(<15,15+$ years $)$

- age at first birth $(<21,21+$ years, nulliparous)

The socioeconomic status was indirectly categorised according to the occupation of the woman (manual/clerical); for housewives the occupation of the husband was used.

\section{Results}

The pattern of answers to the questionnaire was very similar between cases and controls: a third of the subjects filled in the first mailed copy (33.1\% of cases and $31.7 \%$ of controls). An answer from the reminder was obtained in $13.6 \%$ of cases and $17 \cdot 1 \%$ of controls.

A telephone interview was conducted in $46.7 \%$ of cases and $44.3 \%$ of controls, while a face to face interview, usually at home, was necessary in $6.4 \%$ of cases and $6.7 \%$ of controls.

The distribution of cases and controls according to the different variables used in the final model is shown in table I: as expected cases tended to be more frequently divorced $(8.4 \% v$ $2.6 \%, p<0.05$ ), to report more children (at least 3 children: $25.1 \%$ v $21.0 \%$, NS), more abortions (at least 2 abortions: $13.6 \% v 8.5 \%$, NS), a lower age at marriage (first marriage at less than 21 years: $26.1 \% v 13 \%, \mathrm{p}<0.01$ ), and a lower age at first delivery (first delivery at less than 21 years: $20.9 \%$ $v 8.2 \%, \mathrm{p}<0.01$ ). The proportion of current smokers among cases was higher than among controls $(29.8 \% v 18.3 \%, \mathrm{p}<0.05)$.

No differences were found in the socioeconomic level and the place of birth. Controls however tended to have had somewhat more education $(11.3 \% v 6.9 \%$ with $>8$ years of education, NS).

Table II shows the distribution of cases and controls according to the performance of Pap smears (never screened women/women screened at least once), and the estimate of crude and 
Table I Distribution of cases and controls according to different variables used in the model. Values in parentheses are percentages

\begin{tabular}{|c|c|c|c|c|}
\hline Variable & Level & Cases & Con & rols \\
\hline Age (years) & $\begin{array}{l}<45 \\
45-54 \\
55-64 \\
65-74\end{array}$ & $\begin{array}{ll}31 & (16 \cdot 2) \\
44 & (23 \cdot 0) \\
53 & (27 \cdot 8) \\
63 & (33 \cdot 0)\end{array}$ & $\begin{array}{r}89 \\
125 \\
151 \\
175\end{array}$ & $\begin{array}{l}(16 \cdot 4) \\
(23 \cdot 1 \\
(28 \cdot 0) \\
(32 \cdot 5)\end{array}$ \\
\hline Civil status & $\begin{array}{l}\text { Married/widow } \\
\text { Unmarried } \\
\text { Divorced }\end{array}$ & $\begin{array}{rr}158 & (82 \cdot 7) \\
17 & (8 \cdot 9) \\
16 & (8 \cdot 4)\end{array}$ & $\begin{array}{r}474 \\
52 \\
14\end{array}$ & $\begin{array}{r}(87 \cdot 8) \\
(9 \cdot 6) \\
(2 \cdot 6)\end{array}$ \\
\hline Socioeconomic level & $\begin{array}{l}\text { Low } \\
\text { High }\end{array}$ & $\begin{aligned} 145 & (75 \cdot 9) \\
46 & (24 \cdot 1)\end{aligned}$ & $\begin{array}{l}403 \\
137\end{array}$ & $\begin{array}{l}(74 \cdot 6) \\
(25 \cdot 4)\end{array}$ \\
\hline Place of birth & $\begin{array}{l}\text { Florence district } \\
\text { Central-Northern Italy } \\
\text { Southern Italy }\end{array}$ & $\begin{aligned} 106 & (55 \cdot 5) \\
64 & (33 \cdot 5) \\
21 & (11 \cdot 0)\end{aligned}$ & $\begin{array}{r}315 \\
170 \\
55\end{array}$ & $\begin{array}{l}(58.3) \\
(31 \cdot 5) \\
(10 \cdot 2)\end{array}$ \\
\hline Level of education & $\begin{array}{l}\text { High } \\
\text { Low }\end{array}$ & $\begin{array}{rr}13 & (6 \cdot 9) \\
178 & (93 \cdot 1)\end{array}$ & $\begin{array}{r}61 \\
479\end{array}$ & $\begin{array}{l}(11 \cdot 3) \\
(88.7)\end{array}$ \\
\hline Children & $\begin{array}{c}0 \\
1-2 \\
3+\end{array}$ & $\begin{aligned} 25 & (13 \cdot 1) \\
118 & (61 \cdot 8) \\
48 & (25 \cdot 1)\end{aligned}$ & $\begin{array}{r}90 \\
337 \\
113\end{array}$ & $\begin{array}{l}(16 \cdot 6) \\
(62 \cdot 4) \\
(21 \cdot 0)\end{array}$ \\
\hline Abortions & $\begin{array}{l}0 \\
1 \\
2+\end{array}$ & $\begin{aligned} 135 & (70 \cdot 7) \\
30 & (15 \cdot 7) \\
26 & (13 \cdot 6)\end{aligned}$ & $\begin{array}{r}406 \\
88 \\
46\end{array}$ & $\begin{array}{r}(75 \cdot 2) \\
(16 \cdot 3) \\
(8 \cdot 5)\end{array}$ \\
\hline Smoking history & $\begin{array}{l}\text { Non-smokers } \\
\text { Smokers } \\
\text { Ex-smokers }\end{array}$ & $\begin{array}{rr}122 & (63 \cdot 9) \\
57 & (29 \cdot 8) \\
12 & (6 \cdot 3)\end{array}$ & $\begin{array}{r}406 \\
99 \\
35\end{array}$ & $\begin{array}{r}(75 \cdot 2) \\
(18 \cdot 3) \\
(6 \cdot 5)\end{array}$ \\
\hline Age at 1st marriage (years) & $\begin{array}{l}<21 \\
21+ \\
\text { Never married }\end{array}$ & $\begin{array}{rr}50 & (26 \cdot 1) \\
124 & (65 \cdot 0) \\
17 & (8 \cdot 9)\end{array}$ & $\begin{array}{r}70 \\
418 \\
52\end{array}$ & $\begin{array}{r}(13 \cdot 0) \\
(77 \cdot 4) \\
(9 \cdot 6)\end{array}$ \\
\hline Age at menarche (years) & $\begin{array}{c}<12 \\
12-14 \\
15+\end{array}$ & $\begin{aligned} 22 & (11 \cdot 6) \\
136 & (71 \cdot 2) \\
33 & (17 \cdot 2)\end{aligned}$ & $\begin{array}{r}87 \\
376 \\
77\end{array}$ & $\begin{array}{l}(16 \cdot 1) \\
(69 \cdot 6) \\
(14 \cdot 3)\end{array}$ \\
\hline $\begin{array}{l}\text { Age at first birth (years) } \\
\text { Total }\end{array}$ & $\begin{array}{l}21 \\
21+ \\
\text { Nulliparous }\end{array}$ & $\begin{array}{rr}40 & (20 \cdot 9) \\
126 & (66 \cdot 0) \\
25 & (13 \cdot 1) \\
191 & \end{array}$ & $\begin{array}{r}44 \\
406 \\
90 \\
540\end{array}$ & $\begin{array}{r}(8 \cdot 2) \\
(75 \cdot 2) \\
(16 \cdot 6)\end{array}$ \\
\hline
\end{tabular}

\begin{tabular}{|c|c|c|c|c|c|c|}
\hline \multirow[b]{2}{*}{ Cases } & \multicolumn{2}{|c|}{$\begin{array}{l}\text { Pap test } \\
0\end{array}$} & \multicolumn{2}{|l|}{$1+$} & \multicolumn{2}{|c|}{ Total } \\
\hline & 155 & $(81 \cdot 2)$ & 36 & $(18 \cdot 8)$ & 191 & (100) \\
\hline Controls & 282 & $(52 \cdot 3)$ & 258 & $(47 \cdot 7)$ & 540 & $(100)$ \\
\hline Total & 437 & $(59 \cdot 7)$ & 294 & $(40 \cdot 3)$ & 731 & $(100)$ \\
\hline Crude odds ratio matched data & $1^{\star}$ & & $0 \cdot 20$ & & & \\
\hline $\begin{array}{l}\text { Adjusted odds ratio } \\
\text { (logistic model) } \\
95 \% \text { confidence limits }\end{array}$ & $1^{\star}$ & & $\begin{array}{l}0.15 \\
0.09\end{array}$ & -0.25 & & \\
\hline
\end{tabular}

* Reference category

Table II Distribution of cases and controls according to performance of Pap smears (never/at least once). Estimates of crude odds ratios for matched data and adjusted odds ratios (logistic model) for matched data. Figures in parentheses are percentages.

Table III Distribution of cases and controls according to number of Papanicolaou tests. Estimates of crude odds ratios for matched data and adjusted odds ratios for matched data (logistic model). Figures in parentheses are percentages. adjusted odds ratios for matched data. This simple dichotomus analysis shows a strong protective effect of screening: the reduction in risk was about $80 \%$ (odds ratio $0 \cdot 15,95 \%$ confidence limits 0.09-0.25) for women screened at least once in comparison with the never screened women.

This considerable protective effect is also evident in table III, which shows the distribution

\begin{tabular}{|c|c|c|c|c|c|c|}
\hline \multirow[b]{3}{*}{ Cases } & \multicolumn{6}{|c|}{ Number of Pap tests } \\
\hline & \multicolumn{2}{|l|}{0} & 1 & 2 & $3+$ & Total \\
\hline & 155 & $(81 \cdot 1)$ & $20 \quad(10.5)$ & $(4 \cdot 7)$ & $(3 \cdot 7)$ & 191 (100) \\
\hline Controls & 282 & $(52 \cdot 2)$ & $86 \quad(15.9)$ & $58 \quad(10 \cdot 7)$ & $114 \quad(21 \cdot 2)$ & $540 \quad(100)$ \\
\hline Total & 437 & $(59 \cdot 7)$ & $106 \quad(14 \cdot 6)$ & $67 \quad(9 \cdot 1)$ & $121 \quad(16 \cdot 6)$ & $731 \quad(100)$ \\
\hline $\begin{array}{l}\text { Crude odds ratio } \\
\text { matched data }\end{array}$ & $1^{\star}$ & & 0.32 & 0.23 & 0.08 & \\
\hline $\begin{array}{l}\text { Adjusted odds ratio } \\
\text { (logistic model) } \\
95 \% \text { confidence limits }\end{array}$ & $1^{\star}$ & & $\begin{array}{l}0.29 \\
0.15-0.55\end{array}$ & $\begin{array}{l}0.13 \\
0.05-0.31\end{array}$ & $\begin{array}{l}0.06 \\
0.03-0.16\end{array}$ & \\
\hline
\end{tabular}

of cases and controls according to the number of Pap tests carried out $(1,2$ or $3+)$. For women screened only once the reduction in risk was about $70 \%$ (odds ratio $0.29,95 \%$ confidence limits $0 \cdot 15-0 \cdot 55)$, for those screened twice the reduction in risk was more than $80 \%$ (odds ratio $0.13,95 \%$ confidence limit $0.05-0.31$ ) while for women screened at least three times the reduction was about $90 \%$ (odds ratio $0.06,95 \%$ confidence limits $0.03-0 \cdot 16)$.

The data were then analysed simultaneously for the effect of the number of screening tests ( 1 or $2+)$ and the interval since the last test, again using never screened women as the reference category. The results are presented in table IV. For women screened only once, if the test was carried out more than $60+$ months before the date of diagnosis the odds ratio was $0.23(0.09-0.58)$, in the interval $36-59$ months it was $0.33(0.09-1 \cdot 27)$, and for women screened recently (a first test in the last 36 months) it was $0.34(0 \cdot 12-1 \cdot 00)$.

For women with at least two Pap tests the odds ratio was $0.06(0.01-0.23)$ if the last test was carried out more than $60+$ months before; if

ऋ Reference category 


\begin{tabular}{|c|c|c|c|c|}
\hline & & $\begin{array}{l}\text { Never } \\
\text { screened }\end{array}$ & $\begin{array}{l}\text { One Pap } \\
\text { test }\end{array}$ & $\begin{array}{l}\text { At least } \\
2 \text { Pap tests }\end{array}$ \\
\hline $\begin{array}{l}\text { No of cas } \\
\text { No of co } \\
\text { Odds rat }\end{array}$ & $\begin{array}{l}\text { ses } \\
\text { ntrols } \\
\text { io }\end{array}$ & $\begin{array}{l}155 \\
282 \\
1^{\star}\end{array}$ & & \\
\hline $\begin{array}{l}\text { Interval } \\
\text { test (mon } \\
\quad<36\end{array}$ & $\begin{array}{l}\text { since last } \\
\text { ths) } \\
\text { No of cases } \\
\text { No of controls } \\
\text { Odds ratio } \\
95 \% \text { CL }\end{array}$ & & $\begin{array}{c}7 \\
26 \\
0 \cdot 34 \\
(0 \cdot 12-1 \cdot 00)\end{array}$ & $\begin{array}{c}7 \\
96 \\
0 \cdot 07 \\
(0 \cdot 02-0 \cdot 19)\end{array}$ \\
\hline $36-59$ & $\begin{array}{l}\text { No of cases } \\
\text { No of controls } \\
\text { Odds ratio } \\
95 \% \text { CL }\end{array}$ & & $\begin{array}{c}5 \\
15 \\
0 \cdot 33 \\
(0 \cdot 09-1 \cdot 27)\end{array}$ & $\begin{array}{c}6 \\
38 \\
0 \cdot 15 \\
(0 \cdot 05-0 \cdot 42)\end{array}$ \\
\hline$\geqslant 60$ & $\begin{array}{l}\text { No of cases } \\
\text { No of controls } \\
\text { Odds ratio } \\
95 \% \text { CL }\end{array}$ & & $\begin{array}{c}8 \\
46 \\
0 \cdot 23 \\
(0 \cdot 09-0 \cdot 58)\end{array}$ & $\begin{array}{c}3 \\
42 \\
0.06 \\
(0 \cdot 01-0.23)\end{array}$ \\
\hline
\end{tabular}

* Reference category

$\mathrm{CL}=$ confidence limits

Table IV Distribution of cases and controls according to the number of Papanicolaou tests $(0,1,2+)$ and to the interval since last test. Estimates of adjusted odds ratios for matched data (logistic model).

carried out in the interval $36-59$ months before the odds ratio was $0.15(0.05-0.42)$ : while for women screened recently (most recent test in the last 36 months) the odds ratio was $0.07(0.02-$ $0 \cdot 19)$.

Of 100 controls sampled, only 92 women could be interviewed a second time: one had recently died, and the other seven were not traced. The agreement with the screening history obtained from the CSPO computerised archive was good for 81 women $(88.1 \%)$. Four women had been recently screened. The other seven interviewed women, who according to our records had never had a Pap test, reported at least one test performed by a private gynaecologist (three women) or in other public services (four women). Three of these seven women were able to specify the date of the last test. However the quality of information initially provided by many women (before they were told the screening history obtained from the CSPO archive) relating to the date and exact number of Pap tests performed tended to be very poor. Only a minority of the interviewed women had kept the written records which are sent to their address after the performance of each test; in this case they were asked to find the record and check the date and the type of test. Several women confused different types of "gynaecological" tests.

\section{Discussion}

The final report of IARC Working Group on Cervical Cancer Screening, ${ }^{16}$ has established the effectiveness of screening programmes based on cytological smears in reducing mortality from carcinoma of the cervix and the incidence of invasive disease.

In Italy a National Screening Programme for cancer of the cervix uteri has not been implemented and a national policy on this issue is not currently available. A working Committee of the Italian League against Cancer has only recently published guidelines for cancer screening programmes, ${ }^{17}$ recommending a Pap smear every 3 years for the female population between 25 and 60 years of age.

The use of a study design of the case-control type can not only provide information on the effectiveness of these programmes but also on the best interval for carrying out the examinations. One relevant methodological problem relates to the fact that women who tend to participate in prevention programmes for cervical cancer could be those who are less at risk; if the risk factors for cervical cancer are inversely correlated with participation in screening, this "selection bias" could lead to an overestimation of the protection associated with previous Pap tests, when comparing women who have undergone one or more examinations with women who have never been screened. To reduce such bias it has been proposed that a case-control study should be carried out, using a cohort of women screened at least once. ${ }^{18}$ Such a study is currently under way in Florence, using the same data source.

Another potential source of bias could be the differential reporting of the individual screening history when interviewing cases and controls. However, the present population based casecontrol study carried out at CSPO differs from other studies in that the information relating to the number, the date, and results of the screening tests was not collected through interviews but through a computerised archive, ensuring maximum reliability and comparability. Moreover population controls and not hospital controls were used in the study. A sample of controls interviewed a second time, to verify the level of agreement between women and the CSPO archive, showed a good level of reliability and accuracy of this information source.

In general the women did not remember the exact number and the date of smear; those women who reported the date of their smears tended to underestimate the number of tests; others tended to confuse different kinds of examination (Pap test, colposcopy, mammography), as has been found in other studies. ${ }^{19}$

The results of this study provide further evidence that the participation in a centralised cervical screening programme reduces the incidence of invasive cervical cancer. This finding is consistent with the reports of several other case-control studies. ${ }^{13411}$ The results of the present study have been adjusted for several variables relating to the socioeconomic status, smoking history, civil status, reproductive history (number of children, age at first child, age at first marriage, number of abortions, etc.) in order to reduce a possible "selection bias". However adjustment for these several potential confounding variables on the basis of the information collected following a rigid protocol (a first postal questionnaire, a reminder after a few weeks, telephone contacts or a final personal interview) did not substantially affect the estimates of the protective effect of the screening participation. The differences between crude and adjusted odds ratios in this analysis were always rather small. As expected cases tended to be more frequently divorced, to report more children, more abortions, and to be less educated. Furthermore they reported a lower age at marriage and a lower age at first birth. The proportion of current smokers among cases was higher than among controls.

A strong protective effect of the screening participation is shown: the women who had had at 
least one screening test showed a reduction in risk of developing an invasive cervical cancer of about $80 \%$. This considerable protective effect is more evident if we consider the number of Pap tests performed. The odds ratios estimated according to the number of Pap tests carried out show a tendency towards decreasing risk with increasing number of Pap tests. This is possibly due to the positive association between a well known group of risk factors (sexual habits as measured by the number of children, age at marriage, civil status and so on) and the exposure under study (Pap smears). Women who are married and have children tend to be more frequently screened than nulliparous women.

To analyse the role of the interval since the last test we considered the distribution of cases and controls according to the number of Pap tests and according to the interval in months since the last test in comparison with the women who had never been screened. When considering separately two different categories of numbers of tests performed (only one and two or more) the risk is stable across different categories of time intervals since the last test.

Several studies in different countries have evaluated the protection against invasive cervical cancer offered through Pap smears according to the interval since the last test and the number of smears. Overall the results of these studies show a considerable change in the risk of developing cervical cancer with time elapsed since last negative smear. ${ }^{19-21}$ However the results of a study conducted in Manitoba, Canada, ${ }^{22}$ recently published, show no trend of increasing risk with increasing interval since the last test. The risk of invasive cervical cancer according to the interval since the last test is very important in determining how often to rescreen with a previous negative screening test.

In the Florence programme women are invited to a colposcopic examination whenever a class II smear shows several cylindrical cells or various metaplastic cells, or evident signs of hyperkeratosis and parakeratosis. Colposcopic examination is also recommended by the clinician or the midwife collecting the sample whenever the cervix is judged "abnormal" (even in presence of a class I smear). In addition, since 1978 women have had free access to a central colposcopy service on the basis of their gynaecologist's advice, mostly on the occasion of the prescription of contraceptives (usually an intrauterine contraceptive device). Overall since that date about $10 \%$ of the women performing a Pap test in the Florence screening programme have also undergone a colposcopy examination (currently 8000 out of 70000 screened women per year). Colposcopy is therefore not only considered a second level test after a "positive" Pap test, but it is also carried out in women whose Pap tests show only minor "atypical" changes, or sometimes independently of the test result. ${ }^{23}$ Therefore the Florence programme is not based on a single screening test, but could be more exactly considered as a programme including colposcopy in a high proportion of attenders. The resulting programme sensitivity in the recent past could be higher than with the Pap test alone, and this could explain the absence of a trend towards decreasing risk with increasing interval since the last test. However further studies evaluating the specific role of colposcopy in a screening programme for cervical cancer are needed.

This work was supported by a grant from the OERRegione Toscana

1 Clarke EA, Anderson TW. Does screening by "Pap" smears help prevent cervical cancer? A case-control study. Lancet 1979; i: $1-4$.

2 Berrino F, Gatta G, D'Alto M, Crosignani P, Riboli E. Use of case-control studies in evaluation of screening programmes. In: Prorok PC, Miller AB, eds. Screening for cancer (UICC Technical Report Series, Vol. 78). Geneva: International Union Against Cancer, 1984: 29-43.

3 La Vecchia C, Franceschi S, De Carli A, Fasoli M, Gentile A, Tognoni G. "Pap" smears and the risk of cervical neoplasia: quantitative estimates from a case-control study. Lancet 1984; ii: 779-82.

4 Aristizabal N, Cuello C, Correa P, Collazos T, Haenszel W. The impact of vaginal cytology on cervical cancer risks in The impact of vaginal cytology on cervical canc

5 Verbeek ALM, Hendriks JHCL, Holland R, Mravunac M, Sturmans F, Day NE. Reduction of breast cancer mortality through mass screening with modern mammography: first results of the Nijmegen project 1975-1981. Lancet 1984; i: $1222-4$

6 Collette HJA, Day NE, Rombach JJ, de Ward F. Evaluation of screening for breast cancer in a non-randomised study the DOM project) by means of a case control study. Lance 1984; i: 1224-6.

7 Palli D, Rosselli Del Turco M, Buiatti E, Carli S, Ciatto S, Toscani L, Maltoni G. A case-control study of the efficacy of non randomised breast cancer screening program in Florence (Italy). Int $f$ Cancer 1986; 38: 501-4.

8 Oshima A, Hirata N, Ubukata T, Fujimoto I. Evaluation of mass screening program for stomach cancer with a casemass screening program for stomach cancer with a cas
control study design. Int $\mathcal{f}$ Cancer 1986; 38: 829-33.

9 Ebeling K, Nischan P. Screening for lung cancer. Results from a case-control study Int $\mathcal{f}$ Cancer 1987; 40: $141-4$. 10 Sasco AJ, Day NE, Walter SD. Case-control studies for the evaluation of screening. $\mathcal{F}$ Chron Dis 1986; 39: 399-405.

11 Berrino F, Gatta G, D'Alto M, Crosignani P, Riboli E. Efficacy of screening in preventing invasive cervical cancer: a case-control study in Milan, Italy. In: Miller AB, Hakama $M$, Day NE, eds. Screening for cancer of uterine cervix. Lyon: International Agency for Research on Cancer, 1986; 111-23.

12 Shapiro S, Venet W, Strax P, Venet L, Roesner R. Ten-to fourteen-year effect of screening on breast cancer mortality. f Natl Cancer Inst 1982; 69: 349-55.

13 Tabar L, Gad A, Holmerg LH, et al. Reduction in mortality from breast cancer after mass screening with mammography. Lancet 1985; i: 829-32.

14 Geddes M, Amorosi A, Balzi D, et al. Incidenza e mortalita per tumori nella Provincia di Firenze 1985. Quaderni di Oncologia, No 2, Lega Italiana per la Lotta contro i Tumori, 1988.

15 Harrell FE. The PHGLM procedure. In: SUGI supplemental user's guide, 1985 edition. Cary, NC: SAS Institute, 1985: 437-66.

16 IARC Working Group on Evaluation of Cervical Cancer Screening programmes. Screening for squamous cervical cancer: duration of low risk after negative result of cervical cytology and its implication for screening policies. $\mathrm{Br} \mathrm{Med} \mathcal{F}$

17 Malton G, Berrino F, Bruzzi P et al. Raccomandazioni per gli screening in oncologia. Firenze: Lega Italiana per la Lotta contro i Tumori, 1988.

18 MacGregory JE, Moss SM, Parkin DM, Day NE. A case-control study of cervical cancer screening in NorthEast Scotland. Br Med $\mathcal{f} 1985 ; 290: 1543-6$.

19 Walter SD, Clarke EA, Hatcher J, Stitt LW. A comparison of physician and patient reports of Pap smear histories. Clin Epidemiol 1988; 41: 401-10.

20 Lynge E, Poll P. Incidence of cervical cancer following negative smear. $\mathcal{F}$ Epidemiol 1986; 124: 345-52.

21 Clarke EA, Hilditch S, Anderson TW. Optimal frequency of screening for cervical cancer: a Toronto case-control. Lyon UICC No 76, 1986.

22 Day NE. Effect of cervical cancer screening in Scandinavia. Obstet Gynecol 1984; 63: 714-8.

23 Choi NW, Nelson NA. Results from a cervical cancer screening programme in Manitoba, Canada. Lyon: UICC No 76, 1986.

24 Singer A, Walker P, Tay SK et al. Impact of introduction of colposcopy to a district general hospital. $B r$ Med $\mathcal{F} 1984$;
2849-51. 